\title{
AN INEQUALITY FOR MIXED POWER MEANS
}

\section{Christos D. TARnAVAS AND DIMITRIOS D. TARnAVAS}

Abstract. In 1992 Frank Hollad [1] stated the following inequality

$$
\left(A_{1} A_{2} \ldots A_{n}\right)^{\frac{1}{n}} \geqslant \frac{1}{n}\left(G_{1} G_{2} \ldots G_{n}\right)
$$

where $A_{k}, G_{k}, k=1,2, \ldots, n$ are arithmetic and geometric means, respectively, of positive numbers $a_{1}, a_{2}, \ldots, a_{k}$.

In 1994 Kiran Kedlaya [2] gave a combinatorial proof of (1). In 1995 Takashi Matsuda [3] gave another proof of (1).

In 1996 B. Mond and J. Pečarić [5] proved the following generalization of inequality (1) involving power means:

$$
\text { if } s>r \text { then } m_{r, s}(a) \geqslant m_{s, r}(a),
$$

where $m_{r, s}(a)$ is defined by the following definition (1.2).

In this article a more general inequality, which concern weighted power means, is proved.

Mathematics subject classification (1991): 26D15, 26D20.

Key words and phrases: mixed power means, weighted power means, power means, convex.

\section{REFERENCES}

[1] FRANK Holland, On a mixed arithmetic-mean, geometric-mean inequality, Mathematics Competitions 5 (1992), 60-64.

[2] Kiran Kedlaya, Proof of a Mixed Arithmetic-Mean, Geometric-Means Inequality, Amer. Math. Monthly 101 (1994), 355-357.

[3] TAKashi Matsuda, An Inductive Proof of a Mixed Arithmetic-Geometric Mean Inequality, Amer. Math. Monthly 102 (1995), 634-637.

[4] Bullen, P. S., D. S. Mitrinovic And P. M. VAsic, Means and Their Inequalities, D. Reidel Publishing Company, Dordrecht, 1988.

[5] B.MOND AND J.PECARIC, A mixed means inequality, Austral. Math. Soc. Gazette 23 (1996), 67-70. 